\title{
Tratamento de superfície em implantes dentários: uma revisão de literatura
}

\author{
Implant surface treatment: a literature review
}

Fabrizio Lorenzoni e Silva*
Franciely Rodrigues
Saulo Pamato
Jefferson Ricardo Pereira

\section{Resumo}

Introdução: desde a descoberta e o desenvolvimento do estudo da osseointegração, forma, topografia, textura e tratamento da superfície dos implantes têm emergido como uma nova maneira de melhorar a qualidade desses materiais bem como a osseointegração. Objetivo: o objetivo deste estudo foi, por meio de uma revisão da literatura, expor os tipos de tratamento de superfície de implantes dentários, bem como as interações celulares relacionadas a esses materiais e como isso afeta a velocidade e a qualidade da osseointegração. Métodos: o estudo foi desenvolvido mediante levantamento bibliográfico nas bases de dados Lilacs, Medline, SciELO e Bireme, utilizando como palavras-chave tratamentos de superfície, osseointegração, implantes dentários e superfície do implante. Revisão de literatura: a rugosidade superficial e o alto grau de hidrofilicidade são capazes de melhorar os resultados da osseointegração. Ainda, superfícies submetidas a ataque ácido e jateamento, assim como modificadas quimicamente, apresentam resultados clínicos satisfatórios em carregamentos precoces, baixa qualidade óssea e pacientes sistemicamente comprometidos. Considerações finais: embora os estudos demonstrem que os implantes com superfície rugosa apresentam maior área de contato entre o tecido ósseo e a porção externa dos implantes, a literatura não apresenta um consenso quanto ao melhor tipo de tratamento de superfície.

Palavras-chave: Implantes. Osseointegração. Propriedades de Superfície.

\section{Introdução}

Em 1954, Branemark descobriu, indiretamente, por meio de seu clássico estudo que verificava a circulação sanguínea em tíbias de coelhos, o que chamou de osseointegração. Isso permitiu pesquisas posteriores em modelos animais, levando a resultados que possibilitaram o tratamento do edentulismo, por meio de próteses conectadas aos implantes dentários ${ }^{1}$.

O processo de osseointegração é determinante para a obtenção do sucesso nas reabilitações protéticas de rebordos total ou parcialmente edêntulos, utilizando implantes dentários. $\mathrm{O}$ contato direto e estável entre o implante e o osso circundante determina esse sucesso ${ }^{2}$.

A osseointegração efetiva é dependente de características como forma do implante (macroscópica e microscópica), qualidade do titânio, superfície e sua interação químico-biológica com o tecido ósseo. Essa análise guiará escolhas clínicas adequadas, propiciando melhor qualidade e rapidez à osseointegração ${ }^{3-5}$.

A capacidade de osseointegração dos implantes está intimamente ligada a uma densa e resistente película de filme de óxido na superfície do implante, que é formada, espontaneamente, quando o titânio entra em contato com o ar ou com os fluidos fisiológicos, substância responsável pela proteção do titânio contra corrosão e oxidação ${ }^{6}$. A espessura e a

\footnotetext{
Especialista em prótese dentária e em implantodontia. Mestrando em Ciências da Saúde, Universidade do Sul de Santa Catarina, Tubarão, SC, Brasil.

Cirurgiã-dentista, Universidade do Sul de Santa Catarina, Tubarão, SC, Brasil.

*** Especialista em prótese dentária. Mestre e doutorando em Ciências da Saúde, Universidade do Sul de Santa Catarina, SC, Brasil.

**** Especialista em prótese dentária. Mestre e doutor em reabilitação oral, Universidade do Sul de Santa Catarina, Tubarão, SC, Brasil.
} 
estabilidade da camada de óxido formada na superfície do implante tem papel importante na relação do implante como biomaterial, pois corrosão e liberação de íons são indesejáveis, podendo prejudicar a osseointegração ${ }^{7}$.

Características como topografia, molhabilidade, carga de superfície e composição química superficial, em contato com tecido ósseo, definem a velocidade e a qualidade da osseointegração. Essas propriedades propiciam interações osso-implante, como adsorção iônica, absorção de proteínas, comunicação entre as células e superfície do implante, além de sinalização para diferenciação dessas células, levando à união do biomaterial com o osso ${ }^{8}$. Técnicas de tratamento de superfície têm sido propostas a fim de criar uma união bioquímica capaz de acelerar as fases iniciais de neoformação óssea sobre o implante ${ }^{9,10}$.

O presente estudo visa, pelo método de revisão de literatura, uma breve apresentação da história da implantodontia, expondo, sequencialmente, os mecanismos biológicos e mecânicos da osseointegração. O objetivo principal é expor os tipos de tratamento de superfície dos implantes dentários e sua relação quantitativa e qualitativa com a osseointegração.

\section{Revisão de literatura}

Para a identificação dos estudos incluídos ou considerados nesta revisão, foi realizada uma estratégia de busca detalhada nos bancos de dados: Medline e Biblioteca Cochrane, SciELO, Lilacs, PubMed. Foram utilizados como descritores: dental, implant, surface e treatment.

Os critérios de inclusão foram: artigos clínicos, laboratoriais e de revisão que estudassem ou comparassem tratamentos de superfícies dos implantes osseointegráveis disponíveis no mercado. Foram excluídos artigos antigos e aqueles cujo idioma não fosse o inglês ou o português.

\section{Osseointegração}

Branemark fundamentou o conceito de osseointegração durante um estudo sobre circulação sanguínea em tíbias de coelhos, em que ao tentar remover as câmeras de titânio de dentro dessas, verificou-se que estavam ancoradas fortemente ao osso. Após consecutivos estudos para compreender essa reação óssea ao biomaterial, Branemark conceituou osseointegração como sendo uma conexão direta, estrutural e funcional entre osso vital organizado e a superfície de um implante de titânio capaz de receber carga funcional ${ }^{11}$.

Uma grande variedade em tamanhos e formas de implantes tem evoluído e melhorado os resultados clínicos. A pesquisa contínua revela que alterações sutis na forma, no comprimento e na largura dos implantes poderiam influenciar o sucesso da ossseointegração ${ }^{12}$.
Não há consenso na literatura em relação à melhor superfície e mesmo ao formato dos implantes para uma melhor osseointegração. Porém, sabe-se que a geometria do implante deve ter o máximo de contato com o osso, aumentando a interação celular com a superfície do material, assim como distribuir o estresse das cargas mastigatórias. Os implantes dentários podem ser divididos de acordo com o seu formato, seus tipos de conexões protéticas, o tratamento de superfície e a rugosidade. $\mathrm{O}$ formato pode ser cilíndrico, cônico ou híbrido, o tipo de conexão pode ser hexágono externo, interno, conexão tipo cone morse, entre outros menos difundidos ${ }^{9}$.

O comprimento e o diâmetro do implante são importantes fatores na relação de seu contato e ancoragem ao tecido ósseo. Estudos sugerem que o diâmetro seria mais importante que o comprimento quanto à dissipação de forças, principalmente em osso cortical. No entanto, o comprimento do implante, em osso medular, demostrou ter uma importância maior do que o diâmetro no quesito de transmissão de forças ao osso ${ }^{13}$.

O formato do implante, sua geometria, afeta a interação entre o osso e o material, portanto, os implantes dentários são classificados em diferentes grupos de acordo com sua forma. Os principais tipos de implantes são cilíndricos, cônicos, lisos ou rosqueáveis. Vários estudos revelaram que as superfícies de implantes com forma cônica, com descontinuidades geométricas, resultaram em maiores tensões do que as formas mais suaves, tais como cilíndricos ${ }^{14}$.

A estabilidade do implante imediatamente à sua instalação, conhecida como estabilidade primária, acontece de acordo com sua ancoragem óssea, que é dependente de sua forma macroscópica, de sua geometria, e da presença ou não de roscas, assim como da quantidade dessas ${ }^{4}$.

Diferentes modificações nos padrões das roscas, tais como microrroscas perto do pescoço do implante e macrorroscas no meio do corpo e, ainda, uma variedade de roscas de passos alterados têm sido empregadas para acentuar o efeito da ancoragem óssea e induzir o comportamento biomecânico desejado ${ }^{10}$.

Quanto à topografia, os implantes dentários apresentam diferentes graus de rugosidade, fator importante para adesão e fixação celular. Os implantes originais de Branemark usinados apresentavam uma rugosidade entre $0,5 \mu \mathrm{m}$ e $1,0 \mu \mathrm{m}$, que era considerado o ideal. Novos estudos comprovaram que medidas de $1,5 \mu \mathrm{m}$ de rugosidade mostraram resultados melhores ${ }^{4}$.

A superfície do implante em contato com o osso tem sido amplamente estudada nos últimos anos. A evolução da qualidade e da rapidez na osseointegração está intimamente ligada ao tratamento de superfície dos implantes dentários ${ }^{12}$.

Na superfície do implante, ocorre a formação de uma delgada camada de óxido que está associada aos mecanismos de osseointegração. A reação inicial 
dessa camada de óxido com o microambiente peri-implantar é baseada na adsorção de íons e moléculas, resultando na formação de um filme de proteínas. Essa adsorção ocorre rapidamente após o contato com o sangue, sendo importante considerar que as células não se aderem diretamente no titânio, e, sim, na camada proteica adsorvida na superfície. Essas interações parecem contribuir com a ancoragem tardia do implante, influenciando na deposição de tecido ósseo nessa interface ${ }^{15}$.

$\mathrm{O}$ fato de o implante encontrar-se imobilizado no osso, estável, propicia uma interação entre as células osteoblásticas e a superfície reativa do titânio. Micromovimentos podem induzir a migração de células indesejadas, ocasionando uma "fibrointegração" e, consequentemente, a perda do implante ${ }^{1}$.

\section{Adesão celular}

O contato inicial da superfície de titânio ocorre assim que o implante é instalado, devido à presença do coágulo sanguíneo. Dessa forma, haverá uma interação inicial caracterizada pela adesão de plaquetas e fibrinogênio na superfície do implante, a qual apresenta a camada superficial de óxido de titânio. Em seguida, ocorre a adesão de células osteogênicas, resultando na formação de uma rede de fibrina. Assim, a adesão de células osteogênicas ocorre em uma camada de óxido de titânio modificada pelas células sanguíneas. Após a aposição de células sobre a superfície do implante, a deposição e posterior mineralização de matriz óssea são iniciadas ${ }^{10}$.

A adesão de proteínas sanguíneas como o fibrinogênio e as plaquetas à superfície do implante acontece antes da adesão das células osteogênicas, formando uma rede de fibrina. Então, a interação dessas células com a camada de óxido de titânio inicia. A superfície, a topografia e as características químicas superficiais do material guiarão a composição da película de proteínas que será incorporada ao implante, direcionando a osteogênese. Em seguida, sobre a superfície do implante, inicia-se a formação de uma matriz óssea na qual ocorre neoformação tecidual e remodelação, criando-se uma interface entre osso e implante, composta por osso novo e velho ${ }^{16}$.

Implantes com superfície rugosa demonstram um maior sucesso na osseointegração em osso de baixa qualidade comparados aos implantes de superfície lisa. Verificou-se, também, que o aumento da composição de cálcio acima da camada de óxido no implante aumentou a adesão celular devido ao aumento da absorção de proteínas sobre a superfície do titânio ${ }^{17}$.

Nanocaracterísticas superficiais dos implantes afetam, grandemente, as interações celulares. A topografia em nanoescala modifica as propriedades mecânicas individuais das células, interferindo na remodelação, base do citoesqueleto, assim como nas mudanças complexas em membranas celulares ${ }^{18}$.
São classificadas como nanoestruturas aquelas com dimensões de 1 a $100 \mathrm{~nm}$. Destaque-se que $500 \mathrm{~nm}$ já correspondem a $0,5 \mu \mathrm{m}$. Idealmente, a rugosidade necessária para formação óssea de qualidade ocorre quando se tem $1,5 \mathrm{~nm}$ na superfície do implante $^{19}$.

\section{Superfícies de implantes}

Os primeiros implantes dentários foram desenvolvidos sem nenhum tipo de tratamento na sua superfície, eram realizados por um processo de usinagem, o qual resultava em implantes com superfície lisa. Durante muito tempo, esse implante foi concebido como padrão ouro. Estudos experimentais comparando superfícies lisas e rugosas demonstram uma melhor resposta biológica para as últimas. Com a evolução da implantodontia, alterações nas superfícies dos implantes começaram a ser realizadas com intuito de aperfeiçoar a osseointegração ${ }^{15}$.

Os processos de alterações na superfície dos implantes podem ser realizados pelo método de adição, quando é acrescentado algum tipo de material na camada por meio de revestimento de plasma spray, ou subtração, quando se remove parte dessa camada superficial por processos físicos e/ou químicos, tais como abrasão por jateamento ou condicionamento ácido ${ }^{4}$.

A texturização da superfície dos implantes pode influenciar o processo de osseointegração tanto na diferenciação celular, após a colocação do implante, como na quantidade de matriz óssea calcificada ${ }^{4,10}$.

\section{Superfícies usinadas "lisas"}

Esses implantes apresentam pequenas ranhuras que permitem o processo de mineralização do osso em direção ao implante, mas não apresentam uma superfície indutora. Forma-se uma superfície anisotrópica, a qual é responsável por promover o processo de adesão celular e a produção da matriz proteica. O implante usinado tem rugosidade de superfície entre $0,5 \mu \mathrm{m}$ e $1 \mu \mathrm{m}$.

Essa superfície usinada é formada por microrranhuras superficiais resultantes do processo de corte. Esses não recebem tratamento químico ou mecânico, apresentando apenas a macromorfologia de usinagem ${ }^{20}$.

\section{Superfícies texturizadas}

\section{Plasma spray}

O plasma spray é o tipo de tratamento mais comum, feito com a chama ionizada de um gás aquecido entre $10.000^{\circ} \mathrm{C}$ e $30.000^{\circ} \mathrm{C}$, e as partículas são lançadas em grandes velocidades contra o corpo do implante. Após o contato, essas partículas resfriam e se solidificam. O spray de plasma é utilizado para aplicar e incorporar o Ti (titânio) e a HA (hidroxiapatita) na superfície do implante ${ }^{21}$. 


\section{Plasma spray de hidroxiapatita}

O tratamento para recobrimento com nucleação de apatita ocorre por meio de três etapas: tratamento alcalino, tratamento térmico e imersão em solução sintética equivalente ao plasma sanguíneo. Essa camada é formada pela pulverização do spray de plasma de hidroxipatita sobre o implante ${ }^{22}$.

A rugosidade depende do tamanho das partículas, da aderência dessas, da velocidade e distância em que essas foram lançadas contra o implante ${ }^{21}$.

\section{Plasma spray de titânio}

O plasma de spray da titâneo é formado pelo recobrimento do implante com gazes ionizados por aspersão térmica com spray de plasma de titânio. Nesse método, a chama ionizada de um gás é lançada contra a parede do implante com uma temperatura elevada entre $10.000^{\circ} \mathrm{C}$ e $30.000^{\circ} \mathrm{C}$. Com essa alteração, ocorre a aceleração de absorção do sangue devido ao efeito de molhabilidade, aumentando a área de contato superficial e promovendo, assim, a osseointegração $0^{21,22}$.

A partícula de titânio é fundida na superfície, formando uma camada de $50 \mu \mathrm{m}$ de espessura. E o revestimento resultante fica entre $10 \mu \mathrm{m}$ e $40 \mu \mathrm{m}$, aumentando a superfície do implante. Porém, superfícies entre $0,5 \mu \mathrm{m}$ e $2 \mu \mathrm{m}$ já têm uma resposta positiva para osseointegração. Sendo assim, os implantes de superfície tratada com plasma spray de titânio têm sido pouco utilizados, pois aumentam a possibilidade de contaminação bacteriana ${ }^{23}$.

\section{Modificação por feixe laser}

O implante tem a sua superfície modificada por irradiação por meio de feixes de laser produzindo erosões e uma superfície rugosa. É um tratamento considerado limpo por não interagir com nenhum material externo durante o processo de modificação da superfície, em que o feixe de laser age como meio físico no tratamento dessa superfície ${ }^{22}$.

É um método que produz alto grau de pureza e rugosidade suficiente para uma boa osseointegração ${ }^{24}$. E a vantagem sobre os outros tipos de tratamentos de superfície é que esse tratamento pode criar microrretenções orientadas e regulares em pontos definidos na superfície ${ }^{21}$.

Essa técnica não envolve elementos químicos, evitando a contaminação da camada de óxido do titânio. Os tamanhos das rugosidades dependem da intensidade do pulso da fonte emissora ${ }^{20}$.

\section{Jateamento de partículas}

Essa modificação na superfície do implante é bombardeada com partículas de óxido de alumínio ou de titânio, por essa ação, o corpo do implante obtém depressões irregulares. Não deve haver adesão de partículas ao implante, essas servem apenas para criar irregularidades. A rugosidade depende do tamanho das partículas, do tempo e da pressão do disparador ${ }^{20-23}$

Análises em MEV (microscópio eletrônico de varredura) em implantes submetidos ao jateamento de alumínio $\left(\mathrm{AL}_{2} \mathrm{O}_{3}\right)$ demonstram resíduos, provenientes do processo de fabricação, que podem contaminar a superfície do implante, o que seria prejudicial à osseointegração, pois competiriam com o cálcio para a formação de osso. $\mathrm{O}$ uso de óxido de titânio no lugar da alumina tornou-se uma forma de evitar esses efeitos indesejáveis na superfície do implante ${ }^{4}$.

\section{Jateamento seguido de ataque ácido}

As superfícies SLA são tratadas com jatos de areia de granulação grossa (250-500 $\mu \mathrm{m})$, produzindo macrorrugosidades no implante, seguidos por ataque ácido (HCl/H2SO4), que é responsável pela microrrugosidade desse ${ }^{15}$.

Os implantes que são tratados com jateamento de areia seguido de ataque ácido, sendo processados sob atmosfera de nitrogênio e armazenados em $\mathrm{NaCl}$ (cloreto de sódio) isotônico, são denominados SLActive. Esses implantes têm uma estabilidade secundária mais ativa que os demais implantes, sendo que essa ocorre em duas semanas após a instalação do implante no $\mathrm{osso}^{25}$.

Nessa nova técnica, a superfície é hidroxilada, e essa mudança química melhora as estruturas superficiais, que são ideais para a adsorção de proteínas e para promover a intenção imediata do implante no tecido ósseo. A superfície SLActive foi desenvolvida para otimizar a estabilidade do implante em menor tempo e diminuir os riscos do tratamento nas fases iniciais ${ }^{26}$.

\section{Ataque ácido}

O implante por ataque ácido é imerso em uma substância ácida, a qual provoca erosões nesse corpo. A concentração de ácido, o tempo e a temperatura são fatores determinantes da microestrutura da superfície. Sobre a superfície lisa, o processo mais utilizado é o duplo ataque ácido, realizado com o ácido sulfúrico e o hidroclorídrico ${ }^{27}$.

\section{Superfícies nanotexturizadas (anodização)}

No caso de superfícies nanotexturizadas, todos os implantes já vêm com uma camada de óxido na sua superfície, os tratados com anodização, recebem uma camada a mais de óxido, obtidas onde o implante é usado como um ânodo, ativando íons, quando um potencial elétrico é aplicado a esse implante, gera reações de transferência de cargas e íons. Sob controle, o campo elétrico guiará o processo de oxidação que ocorrerá no implante e resultará no aumento da espessura da camada de óxido de titânio $\mathrm{TiO}_{2}$. Com o aumento dessa camada de óxido de 
titânio e a adição de outros elementos, como fosfato $\left(\mathrm{PO}_{4}\right)$, potencializa-se a osseointegração ${ }^{20}$.

A resistência à corrosão e a biocompatibilidade estão relacionadas à presença de uma camada de óxido não reativo, o que impede a formação de tecido fibroso em volta do implante e cria um contato direto com o tecido ósseo ${ }^{23,26}$.

Os implantes com esse tratamento de superfície são menos dependentes de composição química, pois o processo resultante se define por um aumento complementar do contato osso-implante ${ }^{19}$.

\subsubsection{Superfícies biomiméticas}

Em 1990, foi desenvolvido por Abe et al. ${ }^{28}$, um procedimento que permite recobrir a superfície do implante com uma camada uniforme de HA similar à camada biológica, com até $15 \mu \mathrm{m}$ de espessura, chamado método biomimético.

Esse tipo de tratamento de superfície consiste na precipitação heterogênea de fosfato de cálcio sob condições fisiológicas de temperatura e $\mathrm{pH}$ sobre o implante dentário, por meio da utilização de solução de íons semelhantes ao plasma sanguíneo com vistas à deposição de camada de apatita. Uma vez que as moléculas estão integradas à estrutura do material, elas são liberadas gradualmente, sendo, assim, capazes de aumentar a osseocondutividade e potencializar a formação do osso em torno do implante ${ }^{29}$.

O fosfato de cálcio, hoje, apresenta-se como um dos principais biomateriais para reposição e regeneração do tecido ósseo, pois apresenta como características: semelhança com a fase mineral de tecido ósseo, dentes e tecidos calcificados; excelente biocompatibilidade; bioatividade; ausência de toxicidade; taxas de degradação variáveis; osteocondutividade $^{29}$.

Outra vantagem desse tratamento de superfície é que as moléculas biologicamente ativas, como agentes osteogênicos, podem ser precipitadas como componentes inorgânicos para formar uma matriz com propriedades tanto osteoindutora (fatores de crescimento) como osteocondutora (camada de fosfato de cálcio) ${ }^{23,26}$.

Estudos têm demonstrado um contato maior entre osso e implante em superfícies com coberturas biomiméticas com fosfato de cálcio do que em superfícies não tratadas ${ }^{23}$.

\section{Discussão}

Segundo Louropoulou et al. ${ }^{30}$ (2015), os implantes dentais devem integrar-se com três diferentes tipos de tecidos: epitelial, conjuntivo e ósseo, a fim de que possam, de forma previsível, ser realmente duradouros. Para Davies ${ }^{16}$ (1998), existem diversos fatores que influenciam no sucesso do implante dentário, sendo esses a estabilidade primária, a qualidade e a quantidade óssea. Sangata ${ }^{31}$ (2010) afirma que a estabilidade primária é fundamental para a osseointegração, sendo assim, um implante com alta estabilidade primária obterá sucesso e o contrário levará ao insucesso desse implante. Já para Goiato et al. ${ }^{32}$ (2014), os fatores que influenciam na osseointegração são a densidade óssea, a localização do implante na maxila e/ou mandíbula e o comprimento do implante, de modo que a estabilidade primária não foi considerada como requisito principal para a osseointegração.

Para Thakral et al. ${ }^{20}$ (2014), técnicas de texturização nos implantes dentários podem influenciar no estabelecimento da osseointegração, tanto para a diferenciação celular, após a inserção do implante, quanto na matriz óssea calcificada. Ainda conforme Wennerberg e Albrektsson ${ }^{33}$ (2009), as superfícies tratadas resultam em um maior contato osso/ implante (BIC), em relação aos implantes lisos. Assim, os implantes com superfícies texturizadas são indicados para locais com menor BIC ao final da cirurgia. Em contrapartida, Att et al. ${ }^{34}$ (2009) afirmam que o osso se deposita indistintamente em superfícies porosas ou lisas. Dessa forma, a porosidade, então, não seria condição necessária para que ocorresse aposição óssea.

Park et al. ${ }^{35}$ (2015) e Yan et al. ${ }^{36}$ (2013) mostraram que os implantes de $\mathrm{Ti}$ recobertos com plasma spray de hidroxiapatita apresentavam maiores quantidade de osso na interface osso/implante, quando comparados a implantes com superfície lisa.

Segundo De Groot et al. ${ }^{37}$ (1987), os implantes de plasma spray de hidroxiapatita já foram muito estudados e considerados com alto potencial para osseointegração. A força utilizada para remoção dos implantes revestidos por HA no seio leito requer 55 MPa para 3 meses e $62 \mathrm{MPa}$ para 6 meses, o que sugere uma remodelação óssea alta.

Herrero-Climent et al. ${ }^{38}$ (2013) optaram por realizar um estudo comparativo entre as superfícies com plasma spray titânio (TPS) e as jateadas com óxido de titânio. Puderam constatar que a TPS tem um padrão único de formação de matriz óssea quando comparada à outra. Com o auxílio de microscopia de varredura, foi identificado que cada superfície acumulou uma quantidade distinta de matéria orgânica e inorgânica na formação de matriz óssea. Isso sugere que as respostas celulares ocorrem independentemente das propriedades físico-químicas do condicionamento das superfícies.

Nessa linha de raciocínio, Rupp et al. ${ }^{26}$ (2014) confirmam que as superfícies SLActive e SLA não apresentaram diferenças aparentes quando ambas apresentavam a mesma topografia, porém, foram observadas diferenças estatisticamente significantes com duas ou quatro semanas de reparação da $\mathrm{BIC}$ (contato osso/implante). Isso relata que as alterações não foram consequências da topografia, mas que, provavelmente, ocorreram pelas alterações nas estruturas químicas.

Comprovando o estudo de Rupp et al. ${ }^{26}$ (2014), um novo estudo realizado na Suécia por Oates et 
al. ${ }^{39}$ (2007) demonstrou que o aumento na velocidade de formação óssea pode influenciar na estabilidade do implante. As superfícies SLA e SLActive foram analisadas por meio de uma frequência de ressonância quanto à osseointegração. Os autores observaram que o tempo de transição de estabilidade primária para a estabilidade secundária foi de duas semanas para superfície SLActive e de quatro semanas para a SLA. Tais resultados demonstram que a velocidade de formação óssea influencia diretamente a estabilidade do implante.

Huang et al. ${ }^{40}$ (2014) estudou o efeito das modificações químicas e nanotopográficas nas fases iniciais de osseointegração. Foram investigadas as modificações de superfície de jateamento com óxido de $\mathrm{Ti}$, tratamento com flúor e modificações com nanohidroxiapatita, analisadas por meio do torque de remoção e análises histológicas após quatro semanas. Análises das imagens de MEV indicaram a presença de nanoestruturas sobre os implantes quimicamente modificados, constatando a presença de Ti, $\mathrm{O}_{2}, \mathrm{C}$ e $\mathrm{N}$ em todos os grupos estudados. $\mathrm{O}$ torque de remoção foi maior para os implantes com modificações químicas nanotopográficas. Conclui-se que superfícies nanotopograficamente modificadas produziram uma superfície diferenciada com maior aposição óssea, explicando então os resultados maiores para torque de remoção nessa superfície.

\section{Conclusão}

Os principais resultados dos tratamentos de superfícies com intuito de melhorar a osseointegração são: acelerar o tempo de cura, permitir o carregamento antecipado dos implantes, garantir maior conforto para o paciente e otimizar o tempo do profissional. A osseointegração ocorre nas superfícies dos implantes dentais, independentemente se essas são tratadas ou não. Os tratamentos de superfície aprimoram o resultado da osseointegração, principalmente nos estágios iniciais, beneficiando uma aposição óssea com densidade qualitativa e quantitativa. Apesar dos resultados apresentados, a literatura odontológica não é unânime quanto ao melhor tipo de tratamento de superfície.

\section{Abstract}

Introduction: Since the discovery and development of the study on osseointegration, shape, topography, texture, and surface treatment of dental implants have emerged as new ways to improve the quality of these materials, as well as osseointegration. Objective: This study aimed, through a literature review, to expose the types of surface treatment of dental implants, as well as cellular interactions relative to this material and how they affect osseointegration speed and quality. Methods: The study was conducted by a literature survey in Lilacs, Medline, Scielo, and Bireme databases, using as keywords "surface treatments", "osseointegration", "dental implants", and "implant surface". Literature review: Surface roughness and high degree of hydrophilicity are able to improve the results of osseointegration. In addition, surfaces subjected to acid attack and sandblasting, as well as chemically modified surfaces present satisfactory clinical results in early loadings, poor bone quality, and medically compromised patients. Final considerations: Although studies have shown that implants with rough surface have a larger contact area between bone tissue and the outer portion of implants, the literature does not present a consensus as to the best type of surface treatment.

Keywords: Implant. Osseointegration. Surface propecties.

\section{Referências}

1. Albrektsson T, Branemark PI, Hansson HA, Lindstrom J. Osseointegrated titanium implants. Requirements for ensuring a long-lasting, direct bone-to-implant anchorage in man. Acta Orthop Scand 1981; 52(2):155-70.

2. Bernardes SR, Claudino M, Sartori IAM. Análise fotoelástica da união de pilar a implantes de hexágono externo e interno. Implant News 2006; 3(4):355-9.

3. Branemark PI. Osseointegration and its experimental background. J Prosth Dent 1983; 50(3):399-410.

4. Misch CE. Implant design considerations for the posterior regions of the mouth. Imp Dent 1999; 8:376-85.

5. Skalak R. Stress transfer at the implant interface. J Oral Implantol 1988; 13(4):581-93.

6. Kasemo B, Lausmaa J. Biomaterial and implant surfaces: on the role of cleanliness, contamination, and preparation procedures. J Biomed Mater Res 1988; 22(A2 Suppl):145-58.

7. Healy KE, Ducheyne P. Hydration and preferencial molecular absorption on titanium in vitro. Biomaterials 1992; 13:553-47.

8. Buser D, Nydegger T, Oxland T, Cochran DL, Schenk RK, Hirt HP, et al. Interface shear strength of titanium implants with sandblasted and acid-etched surface: a biomechanical study in the maxilla of miniature pigs. J Biomed Mater Res 1999; 45(2):75-83.

9. Elias CN, Oshida JHC, Limad M. Relationship between surface properties, roughness, wettability and morphology) of titanium and dental implant removal torque. J Mech Behav Biomed Mater 2008; 1(3):234-42.

10. Zhao G, Schwartz Z, Wieland M, Rupp F, Geis-Gerstorfer $\mathrm{J}$, Cochran DL, et al. High surface energy enhances cell response to titanium substrate microstructure. J Biomed Mater Res A 2005; 74:49-58.

11. Brånemark PI, Breine U, Adell R, Hansson BO, Lindström J, Ohlsson A. Intra-osseous anchorage of dental prosthesis I. Experimental studies. Scand J Plast Reconstru Surg 1970; 9-75.

12. Lee JH, Frias V, Lee KW, Wright RF. Effect of implant size and shape on implant success rates: a literature review. J Prosthet Dent 2005; 94:377-81.

13. Shemtov-Yonga K, Rittel D, Levin L, Machtei EE. Effect of dental implant diameter on fatigue performance. Part I: mechanical behavior. Clin Implant Dent Relat Res 2014; 16(2):172-7. 
14. Seth S, Kalra P. Effect of dental implant parameters on stress distribution at bone-implant interface. Inter J Sci Res 2013; 2:121-4.

15. Novaes AB, Souza SL, Barros RR, Pereira KK, Iezzi G, Piattelli A. Influence of implant surfaces on osseointegration. Braz Dent J 2010; 21:471-81.

16. Davies JE. Mechanisms of endosseous integration. Int $\mathrm{J}$ Prosthodont 1998; 11:391-401.

17. Suh JY, Iwara J, Clore GM. Effects of a novel calcium titanatecoating on the osseointegration of blasted endosseous implants in rabbit tibiae. Clin Oral Implants Res 2007; 18:362-9.

18. Mendonça G, Mendonça DBS, Simões LGP, Araújo AL, Leite ER, Golin AL, et al. Nanostructured alumina-coated implant surface: effect on osteoblast-related gene expressionad boneto-implant contact in vivo. Int $\mathrm{J}$ Oral Maxilofac Implants $2009 ; 24(2): 205$.

19. Meirelles L. The effect of chemical and nanotopographical on the early stages of osseointegration. Int J Oral Maxillofac Implants 2008; 23(4):641-7.

20. Thakral G, Thakral R, Sharma N, Seth J, Vashisht P. Nanosurface - the future of implants. J Clin Diagn Res 2014; 8(5):ZE07-10

21. Galli S, Jimbo R, Andersson M, Bryington M, Albrektsson T. Surface characterization and clinical review of two commercially available implants. Implant Dent 2013; 22(5):507-18.

22. Naves MM, Menezes HH, Magalhães D, Ferreira JA, Ribeiro SF, de Mello JD, et al. Effect of Macrogeometry on the Surface Topography of Dental Implants. Int J Oral Maxillofac Implants 2015; 30(4):789-99.

23. Colombo JS, Satoshi S, Okazaki J, Crean SJ, Sloan AJ, Waddington RJ. In vivo monitoring of the bone healing process around different titanium alloy implant surfaces placed into fresh extraction sockets. J Dent 2012; 40(4):338-46.

24. Berardi D, De Benedittis S, Scoccia A, Perfetti G, Conti P. New laser-treated implant surfaces: a histologic and histomorphometric pilot study in rabbits. Clin Invest Med 2011; 34(4):E202

25. Klein MO, Bijelic A, Ziebart T, Koch F, Kämmerer PW, Wieland M, et al. Submicron scale-structured hydrophilic titanium surfaces promote early osteogenic gene response for cell adhesion and cell differentiation. Clin Implant Dent Relat Res 2013; 15(2):166-75.

26. Rupp F, Gittens RA, Scheideler L, Marmur A, Boyan BD, Schwartz Z, et al. A review on the wettability of dental implant surfaces I: theoretical and experimental aspects. Acta Biomater 2014 ; 10(7):2894-906.

27. Schlee M, Pradies G, Mehmke WU, Beneytout A, Stamm M, Meda RG, et al. Prospective, Multicenter Evaluation of Trabecular Metal-Enhanced Titanium Dental Implants Placed in Routine Dental Practices: 1-Year Interim Report From the Development Period (2010 to 2011). Clin Implant Dent Relat Res 2015; 17(6):1141-53.

28. Abe Y, Kokubo T, Yamamuro T. Apatite coating on ceramics, metals and polymers utilizing a biological process. J Mater Sci Mat Med 1990; 1:233-38.

29. Kurtz SM, Kocagöz S, Arnholt C, Huet R, Ueno M, Walter WL. Advances in zirconia toughened alumina biomaterials for total joint replacement. J Mech Behav Biomed Mater $2014 ; 31: 107-16$

30. Louropoulou A, Slot DE, Van der Weijden F. Influence of mechanical instruments on the biocompatibility of titanium dental implants surfaces: a systematic review. Clin Oral Implants Res 2015; 26(7):841-50.
31. Sangata M. Immediate loading of dental implant after sinus floor elevtion with osteotome technique: a clinical report and preliminary radiographic results. J Oral Implantol 2010; 36(6):485-9.

32. Goiato MC, dos Santos DM, Santiago JF Jr, Moreno A, Pellizzer EP. Longevity of dental implants in type IV bone: a systematic review. Int $\mathrm{J}$ Oral Maxillofac Surg 2014; 43(9):1108-16.

33. Wennerberg A, Albrektsson T. Effects of titanium surface topography on bone integration: a systematic review. Clin Oral Impl Res 2009; 20(4):172-84

34. Att W, Yamada M, Ogawa T. Effect of titanium surface characteristics on the behavior and function of oral fibroblasts. Int J Oral Maxillofac Implants 2009; 24(3):419-31.

35. Park EJ, Song YH, Hwang MJ, Song HJ, Park YJ. Surface Characterization and Osteoconductivity Evaluation of Micro/Nano Surface Formed on Titanium Using Anodic Oxidation Combined with $\mathrm{H} 2 \mathrm{O} 2$ Etching and Hydrothermal Treatment. J Nanosci Nanotechnol 2015; 15(8):6133-6.

36. Yan J, Sun JF, Chu PK, Han Y, Zhang YM. Bone integration capability of a series of strontium-containing hydroxyapatite coatings formed by micro-arc oxidation. J Biomed Mater Res A $2013 ; 101(9): 2465-80$

37. De Groot K, Geesink R, Klein CPA. Plasma sprayed coatings of hydroxylapatite. J Biomed Mat Res 1987; 21(12):1375-81.

38. Herrero-Climent M, Lázaro P, Vicente Rios J, Lluch S, Marqués $\mathrm{M}$, Guillem-Martí $\mathrm{J}$, et al. Influence of acid-etching after grit-blasted on osseointegration of titanium dental implants: in vitro and in vivo studies. J Mater Sci Mater Med 2013; 24(8):2047-55.

39. Oates TW, Valderrama P, Bischof M, Nedir R, Jones A, Simpson J, et al. Enhanced implant stability with a chemically modified SLA surface: a randomized pilot study. Int J Oral Maxillofac Implants 2007; 22(5):755-60.

40. Huang Y, He J, Gan L, Liu X, Wu Y, Wu F, Gu ZW. Osteoconductivity and osteoinductivity of porous hydroxyapatite coatings deposited by liquid precursor plasma spraying: in vivo biological response study. Biomed Mater 2014; 9(6):065007.

Endereço para correspondência:

Jefferson Ricardo Pereira

Rua Recife, 200, apart. 601

Bairro Recife

88790-000 Tubarão, SC

Telefone: (48) 36327763

E-mail: jeffripe@rocketmail.com

Recebido: 05/08/15. Aceito: 13/06/16. 